This item was submitted to Loughborough's Research Repository by the author.

Items in Figshare are protected by copyright, with all rights reserved, unless otherwise indicated.

\title{
Development and validation of an empirical equation to predict wet fabric skin surface temperature of thermal manikins
}

PLEASE CITE THE PUBLISHED VERSION

http://www.jfbi.org/

\section{PUBLISHER}

(C) Textile Bioengineering and Informatics Society Ltd

\section{VERSION}

VoR (Version of Record)

\section{LICENCE}

CC BY-NC-ND 4.0

\section{REPOSITORY RECORD}

Wang, Fa-Ming, Kalev Kuklane, Chuan-Si Gao, Ingvar Holmer, and George Havenith. 2019. "Development and Validation of an Empirical Equation to Predict Wet Fabric Skin Surface Temperature of Thermal Manikins". figshare. https://hdl.handle.net/2134/11717. 
This item was submitted to Loughborough's Institutional Repository (https://dspace.lboro.ac.uk/) by the author and is made available under the following Creative Commons Licence conditions.

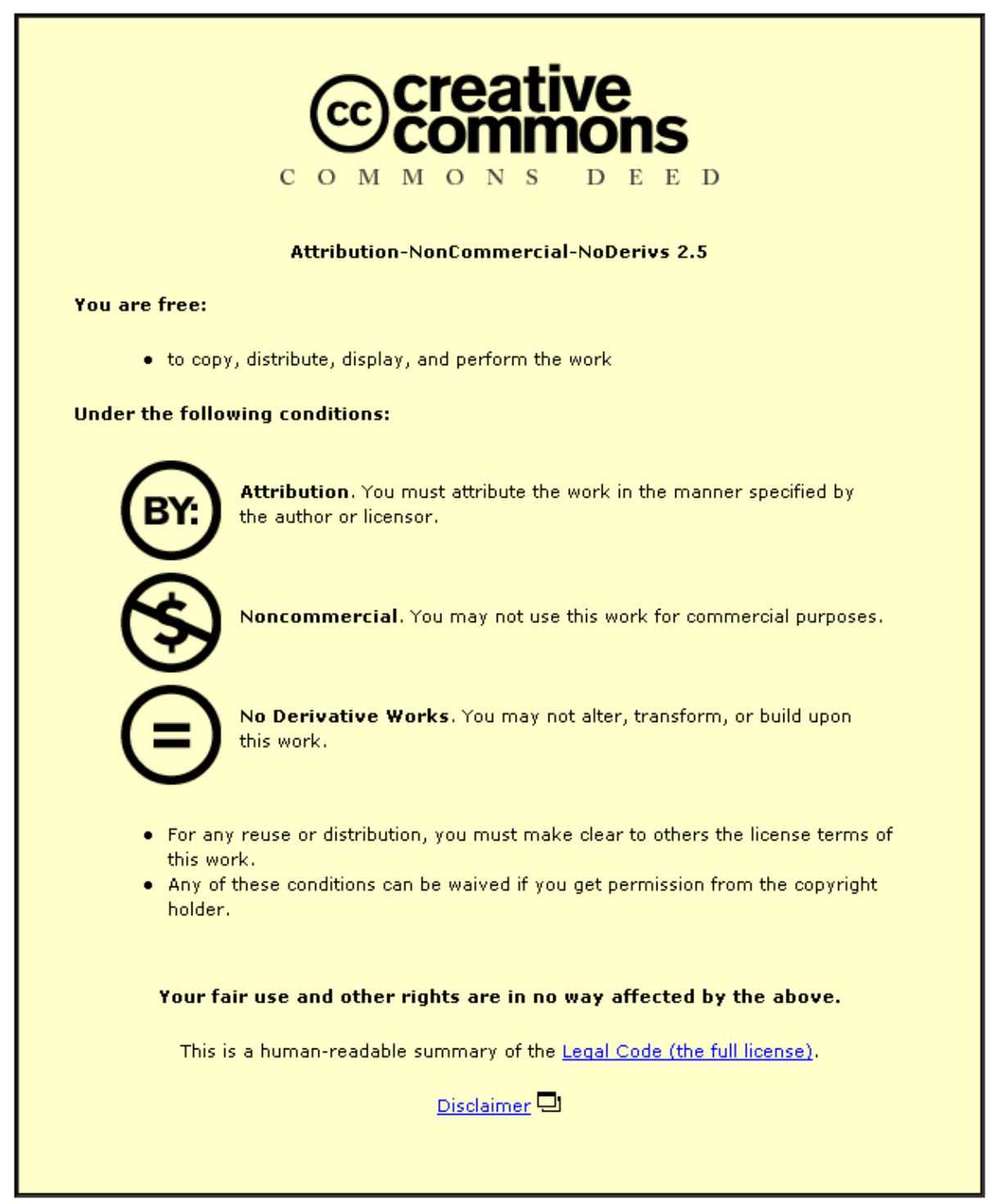

For the full text of this licence, please go to: http://creativecommons.org/licenses/by-nc-nd/2.5/ 


\title{
Development and Validation of an Empirical Equation to Predict Wet Fabric Skin Surface Temperature of Thermal Manikins
}

\author{
Fa-Ming Wang $^{1 *}$, Kalev Kuklane ${ }^{1}$, Chuan-Si Gao ${ }^{1}$, Ingvar Holmér ${ }^{1}$, George Havenith ${ }^{2}$ \\ ${ }^{1}$ Thermal Environment Laboratory, Division of Ergonomics and Aerosol Technology, Department of Design \\ Sciences, Faculty of Engineering, Lund University, Lund 221 00, Sweden \\ ${ }^{2}$ Environmental Ergonomics Research Centre, Department of Ergonomics, Loughborough University, \\ Loughborough, UK
}

\begin{abstract}
Thermal manikins are useful tools to study clothing comfort and environmental ergonomics. The simulation of sweating can be achieved by putting a highly wicking stretchable knit fabric "skin" on top of the manikin. However, the addition of such a fabric skin makes it difficult to accurately measure the skin surface temperature. Moreover, it takes considerable amount of time to measure the fabric skin surface temperature at each test. At present the attachment of temperature sensors to the wet fabric skin is still a challenge. The distance of the sensors to the fabric skin could significantly influence the temperature and relative humidity values of the wet skin surface. Hence, we conducted an intensive skin study on a dry thermal manikin to investigate the relationships among the nude manikin surface temperature, heat losses and the fabric skin surface temperature. An empirical equation was developed and validated on the thermal manikin 'Tore' at Lund University. The empirical equation at an ambient temperature $34.0^{\circ} \mathrm{C}$ is $T_{\text {sk }}=34.00$ $0.0103 \mathrm{HL}$. This equation can be used to enhance the prediction accuracy of wet fabric skin surface temperature and the calculation of clothing evaporative resistance.
\end{abstract}

Keywords: Fabric skin, thermal manikin, skin surface temperature, isothermal, empirical equation, clothing ensemble.

\section{Introduction}

Thermal manikins are widely used in governmental, industrial and academic research institutes to evaluate the environmental and occupational protective capabilities of clothing, footwear, handwear and even headgear [1]. It is well documented that thermal manikins are one of the most ideal instruments for measuring the thermal and evaporative resistances of clothing ensembles [2-4]. Although thermal manikins have served research and development purposes for about 70 years [3], the simulation of human sweating in thermal manikins is still a great challenge.

Our human body has 3 to 4 million eccrine sweat glands, with an average distribution of 150 to 340 per square centimetre [5]. They are mostly found in numerous quantities on the palms and soles and then, in decreasing order, on the head, trunk, and extremities. The specific function of sweat glands is to secrete water upon the skin surface so that it can cool the human skin when it evaporates. Man can perspire as much as several litres per hour and 10 litres per day [6]. Sweating is the most important effector function to reduce thermal strain of humans who are working in a hot environment.
Currently, there are three major approaches to sweating simulations in thermal manikins used worldwide [7-9]: pre-wetted high wicking fabric covering a dry thermal manikin, thermal manikins with pumps to regulate the water supply through 'sweating' glands to a wicking knit fabric, and sweating fabric manikins based on a water filled body covered with waterproof but permeable fabric, such as Gore-tex fabrics.

The embedded heating wires under the thermal manikin surface heat each segment to a set temperature. The wet skin test is conducted to determine the clothing evaporative resistance. As it is the manikin's skin temperature that is controlled, and not the wet skin, the evaporative cooling of the wet skin layer may generate a temperature difference between the wet skin surface and the controlled nude manikin surface. It is anticipated that this temperature difference is related to the overall evaporative heat loss of the manikin (and in non iso-thermal ambient conditions on the total heat loss). To some extent, the accuracy of 'measurement' of the wet skin surface temperature determines the accuracy of evaporative resistance of clothing ensembles. However, no data have been published on putting temperature sensors on the wet skin surface to accurately measure the skin surface temperature. 
Informally, various labs have reported attempts estimating skin temperature correction factors (Redortier, Havenith, Ueno, Kuklane, Burke; personal communications at ICEE 2007), but with limited success. Havenith (personal communication) studied this phenomenon using an infra-red camera on a thermal manikin 'Newton' [10] to measure surface temperatures and developed a prediction equation, which was not published either. Thus it was deemed useful to perform a study to measure wet skin surface temperatures and develop a series of skin temperature prediction equations relating the wet surface temperature to the manikin nude surface temperature and the total heat loss. Ideally, with such skin equations, we can predict the wet skin surface temperature without even using temperature sensors, avoiding a lot of technical issues. Moreover, such skin set equations can also be expected to predict the skin surface temperature for the wet skin with clothing ensembles worn on top.

In this study, a well fitted pre-wetted knit fabric skin was placed on top of the dry heated thermal manikin 'Tore' to simulate a wetted skin by sweating. The prewetted skin surface temperatures were measured on an undressed manikin by 18 digital temperature and relative humidity integrated sensors at an isothermal condition of $34.0{ }^{\circ} \mathrm{C}$. A correction equation for the prediction of skin's outer surface temperatures was developed based on the skin's inner surface temperatures measured. Finally, an empirical equation for the skin surface temperature prediction was developed and validated while the manikin was dressed with four different functional clothing ensembles.

\section{Methods}

\subsection{Thermal manikin}

A Swedish 17-segment thermal manikin 'Tore' was used in this study (Figure 1). 'Tore' is made of plastic foam with a metal frame inside to support body parts and for joints [11]. It is the size of an average Swedish male of 1980s. Its height is $170 \mathrm{~cm}$, chest and waist circumferences are 94 and $88 \mathrm{~cm}$ respectively, with a total heated body area of $1.774 \mathrm{~m}^{2}$. The manikin surface temperature can be controlled independently within $\pm 0.5{ }^{\circ} \mathrm{C}$, and the total heat input required to achieve this was accurately measured within $\pm 2 \%$.

The heat input is a direct measure of the heat loss from the manikin [12]. When put in isothermal conditions $\left(T_{s k}=T_{a}=T_{r}\right)$ this directly reflects the evaporative heat loss, as radiative and convective gradients will be zero.

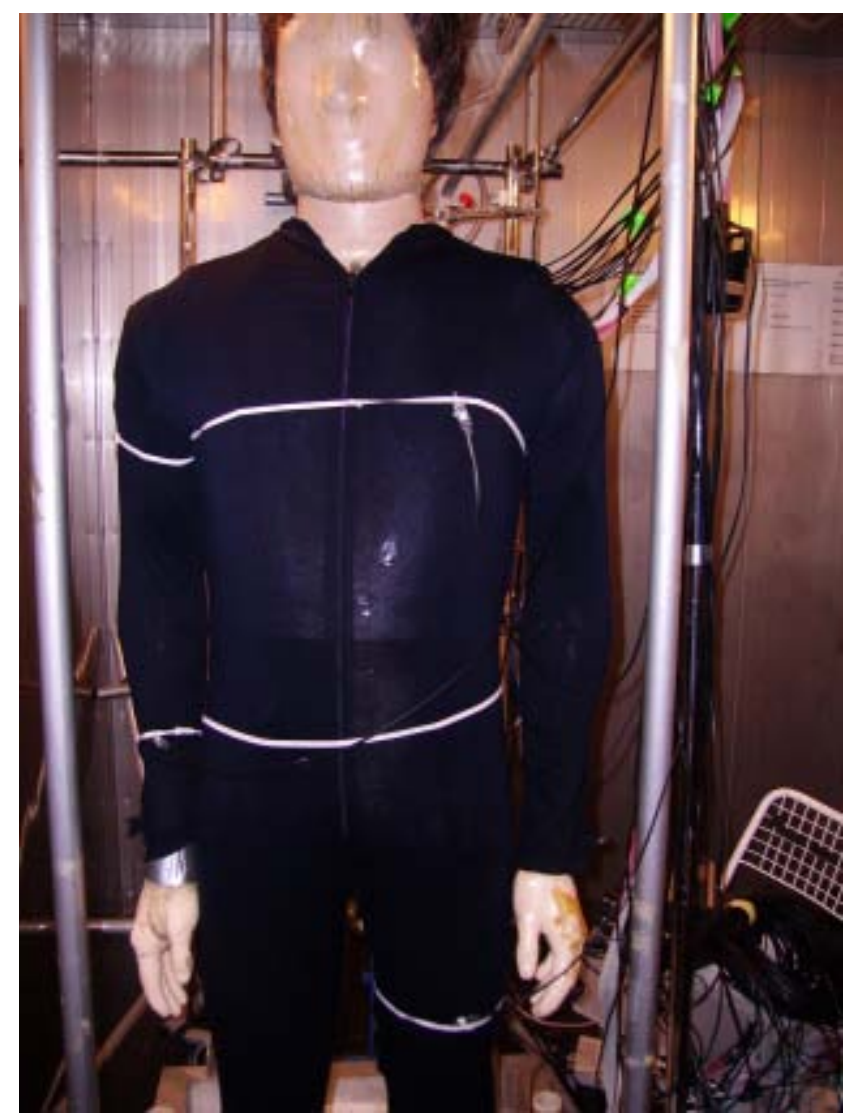

Figure 1 The thermal manikin 'Tore' in the climatic chamber.

\subsection{Skin layer}

A knit cotton fabric skin was used in this study. The skin was specially designed for the thermal manikin 'Tore' to fit it tight. Before each wet test, the cotton skin was rinsed in a washing machine (Electrolux $\mathrm{W} 3015 \mathrm{H}$, Sweden) for 4 minutes and then centrifuged for 4 seconds to ensure no water would drip from the skin.

\subsection{Test conditions}

The manikin surface temperature was set to $34.0{ }^{\circ} \mathrm{C}$. All skin tests were conducted at an isothermal condition where the ambient temperature was $34.0{ }^{\circ} \mathrm{C}$. Three platinum air temperature sensors set at the height of $0.1,1.1$ and $1.7 \mathrm{~m}$ were used to record the ambient temperatures. The air velocity was controlled at $0.33 \pm 0.09 \mathrm{~m} / \mathrm{s}$ for all tests. The air inlets in the climatic chamber are on the ceiling and an air outlet is on the 
bottom of one side wall. In the determination of sensor attachment section, the partial vapour pressures in the climatic chamber were set at $1,2,3$ or $4 \mathrm{kPa}$, respectively (the observed relative humidities were 25.6, 40.9, 52.5 and $72.2 \%$, respectively). Eighteen digital temperature and humidity integrated sensors (SHT75, CMO Sensirion, Switzerland, accuracy: \pm 0.3 $\left.{ }^{\circ} \mathrm{C}\right)$ were used in the tests. Twelve sensors were attached to the nude manikin surface at 12 positions (the left upper arm, left lower arm, right lower arm, right upper arm, right scapula, right lower chest, left upper chest, left lower buttocks, right shin, left calf, right posterior thigh, and the left anterior thigh) using waterproof surgical tapes (3M, USA). Other six sensors were attached to the wet skin outer surface at 6 points (the left anterior thigh, left upper chest, left lower buttock, right upper arm, right lower arm and the right upper back) using white thread rings (Resårband Gummilitze Elastic Braid, Sweden). Both sensor attachments are shown in Figure 2. In the equation validation part, four functional clothing ensembles were used. All tests were conducted at an ambient temperature of $34.0{ }^{\circ} \mathrm{C}$ and the $\mathrm{RH}$ value was $37.6 \%$. The measurements of thermal and evaporative resistances of the four clothing ensembles were conducted following ISO 15831 and ASTM F 2370 [13, 14]. The details of the four functional clothing ensembles are listed in Table 1.

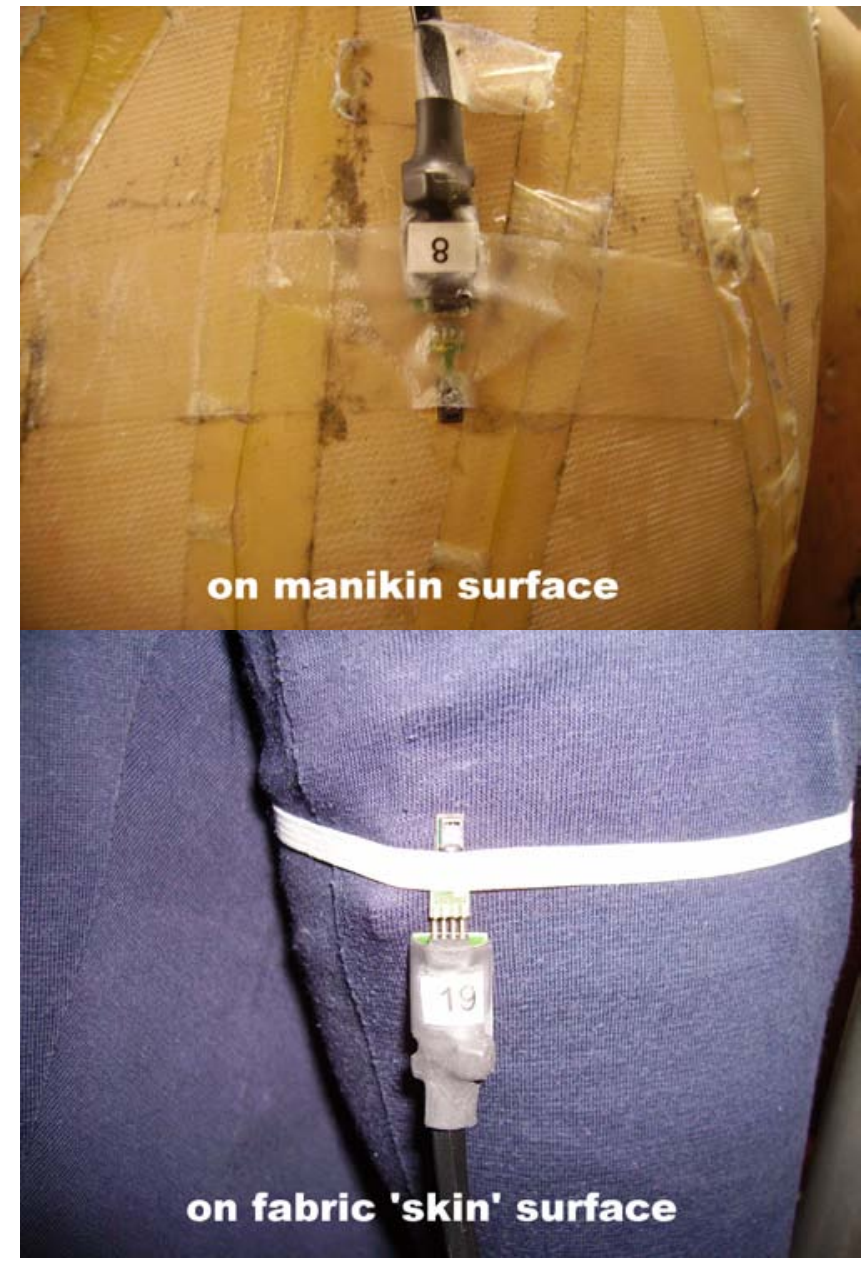

Figure 2 Sensor attachments applied in the study.

Table 1 Details of four functional clothing ensembles

\begin{tabular}{ccccc}
\hline Code & $\begin{array}{c}\text { Clothing } \\
\text { ensembles }\end{array}$ & $\begin{array}{c}\text { Total } \\
\text { weight } \\
\mathrm{g}\end{array}$ & $\begin{array}{c}\text { Thermal } \\
\text { resistance } \\
\text { clo }\end{array}$ & $\begin{array}{c}\text { Evaporative } \\
\text { resistance } \\
\mathrm{Pa} \mathrm{m}^{2} / \mathrm{W}\end{array}$ \\
\hline L & $\begin{array}{c}\text { t-shirt, briefs, short pants, socks, sports shoes } \\
\text { t-shirt, briefs, long trousers with reflective } \\
\text { materials, socks, shoes }\end{array}$ & $\begin{array}{c}1692 \\
2211\end{array}$ & 1.05 & 1.20 \\
MIL & $\begin{array}{c}\text { jacket, long trousers, net t-shirt, briefs, socks, } \\
\text { sports shoes }\end{array}$ & 2132 & 1.65 & 25.7 \\
CLM & $\begin{array}{c}\text { polyamide overall laminated with Gore-tex } \\
\text { membrane, t-shirt, briefs, socks, sports shoes }\end{array}$ & 3570 & 1.68 & 72.1 \\
\hline
\end{tabular}

Note: L: light series clothing; HV: high vision series clothing; MIL: military series clothing; CLM: climber series clothing.

Table 2 The results of Paired Samples t-test

\begin{tabular}{|c|c|c|c|c|c|c|c|c|}
\hline & \multirow[t]{2}{*}{ mean } & \multirow[t]{2}{*}{ SD } & \multirow{2}{*}{$\begin{array}{l}\text { Std Error } \\
\text { mean }\end{array}$} & \multicolumn{2}{|c|}{$\begin{array}{c}95 \% \text { Confidence Interval } \\
\text { of the Difference }\end{array}$} & \multirow[t]{2}{*}{$\mathrm{t}$} & \multirow[t]{2}{*}{$\mathrm{df}$} & \multirow[t]{2}{*}{ Sig. (2-tailed) } \\
\hline & & & & Lower & Upper & & & \\
\hline Pair $t_{\text {in }}-t_{\text {out }}$ & -0.0133 & 0.03781 & 0.00690 & -0.02745 & 0.000079 & -1.931 & 29 & 0.063 \\
\hline
\end{tabular}




\section{Results and discussion}

\subsection{Determination of the temperature sensor attachment}

The attachment of temperature sensors using thread rings onto the wet skin outer surface was difficult and time-consuming. The sensors should be attached to the skin outer surface before each test and removed after the test. On the other hand, the distance to the skin surface greatly affects the temperature and RH values. Besides, the impermeable sticky tapes cannot be applied on the wet surface as they might constrict the evaporation and malfunction when attached to the wet flat surface. An alternative to solve these problems was that all the sensors were attached on the nude manikin surface to measure the wet skin inner surface temperature. In this case, a correction for wet skin outer surface temperatures should be developed based on these inner surface temperatures observed in the test. For this reason, we conducted a temperature correction test before the development of the skin empirical equation. The correction aims to simplify the measurement and save the preparation time caused due to the drying of the out wet skin after 40 to $50 \mathrm{~min}$.

The temperature values were recorded at 10 seconds interval. The mean skin inner and outer surface temperatures were calculated based on each minute data during the stable state period of each test condition. The total sample size was 30.The Paired-
Samples t-tests were performed to determine whether there are significant mean temperature differences between the skin inner surface and outer surface. The significant level was set at 0.05 . The results are displayed in Table 2 . It can be easily seen that the $P$ value was 0.063 . The null hypothesis should be accepted accordingly. Therefore, there are no significant temperature differences between the wet skin inner surface and outer surface. Therefore, the temperatures measured on the inner skin surface can be deemed as values measured on the outer skin surface. This simplifies the measurement and most importantly, the measurement accuracy is almost the same.

\subsection{Development of a wet fabric skin surface prediction equation}

A special program [15] was used to record the total heat loss from the nude (only wet skin) manikin. The temperatures and relative humidities of the wet skin inner surface were recorded every 10 seconds by the Sensirion program (Sensirion AG, Switzerland). Nude skin tests were performed twice at 4 different water vapour pressure levels mentioned in the test conditions part (isothermal conditions, totally 8 tests). Based on the data of the nude thermal manikin, such as surface temperature, wet fabric skin surface temperature and the total heat loss, a scatter chart with markers was plotted (Figure 3).

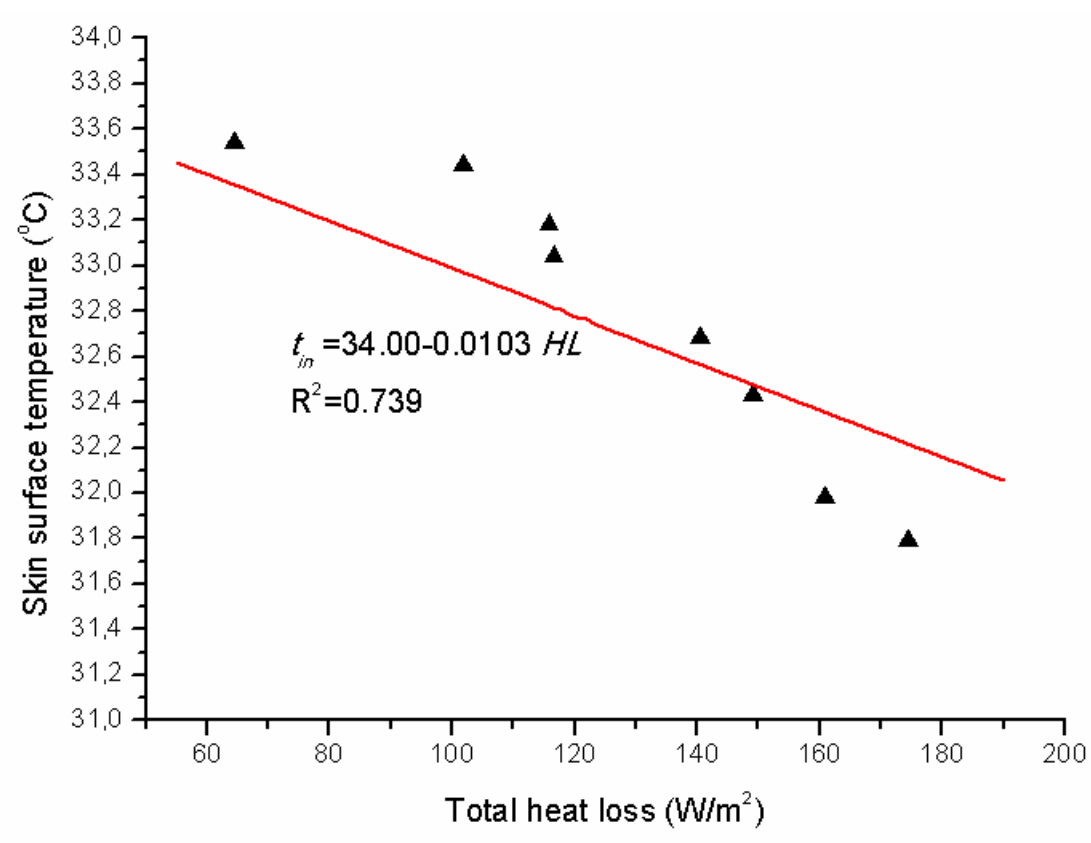

Figure 3 An empirical equation for prediction of the wet skin outer surface temperature at $34.0^{\circ} \mathrm{C}$. 
Considering the fact that the skin surface will not cool down if there is no evaporative heat loss, a linear regression equation with a forced point $(0,34.0)$ was developed accordingly. It can be deduced from Figure 3 that the linear equation fits the 8 points well and the correlation factor is 0.86 . The equation can be expressed as follows

$$
T_{s k}=34.00-0.0103 H L
$$

where, $H L$ is the total heat loss from the thermal manikin, $\mathrm{W} / \mathrm{m}^{2}$.

\subsection{Validation of the wet skin temperature prediction equation}

Four functional clothing ensembles were used in this section for the validation of the skin temperature correction equation. The clothing ensembles were mainly used for outdoor activities such as camping, road and power line construction, mining and military training. Each test was repeated twice for 4 different clothing ensembles. The observed and predicted wet skin surface temperatures for each clothing ensemble are plotted in Figure 4.

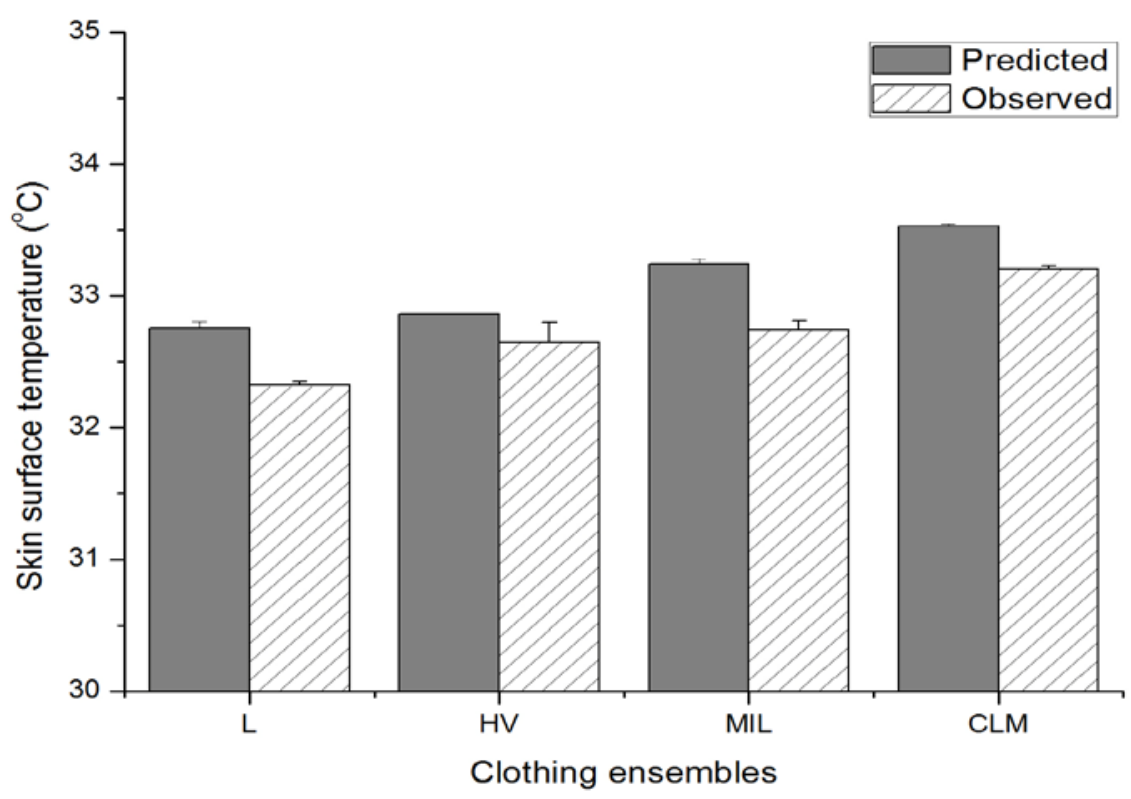

Figure 4 Predicted and observed skin surface temperatures for four functional clothing ensembles at $34.0^{\circ} \mathrm{C}$.

The root mean squared deviation (RMSD) was used to compare the statistical evaluation between the predicted values and the observed data. The RMSD $[16,17]$ is a frequently-used measure of differences between values predicted by a model and the values actually observed from the thing being modelled or estimated. The RMSD is defined as

$$
R M S D=\sqrt{\frac{\sum_{i=1}^{n} x_{i}^{2}}{n}}
$$

where, $x_{i}$ is the difference between the predicted and observed at each test condition; $n$ is the numbers of comparison.

The heat loss values observed from the sweating thermal manikin in these four functional clothing ensembles ranged from 45.9 to $125.9 \mathrm{~W} / \mathrm{m}^{2}$. The differences between predicted skin inner surface temperatures and values observed ranged from 0.30 to $0.52{ }^{\circ} \mathrm{C}$. The RMSDs for clothing ensembles $\mathrm{L}, \mathrm{HV}$, MIL and CLM are 0.34, 0.26, 0.46 and 0.31, respectively. The averaged RMSD for all 8 tests is 0.34 . Therefore, the predicted values are slightly greater than the observed wet fabric skin surface temperature. However, the prediction is still in an acceptable range $\left( \pm 0.5{ }^{\circ} \mathrm{C}\right)$.

Moreover, Havenith (personal communication, Havenith, Kuklane and Ueno, 2008) analysed wet skin surface temperatures of a thermal manikin 'Newton' by infra-red analysis of surface temperatures immediately after stripping clothing. The equation is

$$
T_{s k}=34.13-0.012 H L
$$


Based on the heat loss values observed in the validation tests, the predicted mean skin outer surface temperatures by Eq. 3 ranged from 32.53 to $33.58{ }^{\circ} \mathrm{C}$. Similarly, the RMSDs for clothing ensembles L, HV, MIL and CLM are 0.25, 0.29, 0.46 and 0.36, respectively. The mean RMSD for all 8 test garments is also 0.34. Hence, the predicted skin surface temperatures by Eqs. 1 and 3 are relatively similar.

\section{Conclusions}

We developed an empirical equation for the prediction of wet fabric skin surface temperature of the thermal manikin 'Tore'. The empirical equation was validated on four different functional clothing ensembles at the same isothermal conditions. The RSMD of the 8 validation tests is 0.34 . Therefore, the empirical equation slightly overestimates the skin surface temperature, but the predicted value is still in an acceptable range. The empirical equation can be described as

$$
T_{s k}=34.00-0.0103 H L
$$

In this paper, we developed an empirical equation for the thermal manikin 'Tore' at an isothermal condition of $34.0{ }^{\circ} \mathrm{C}$. The prediction equation developed in this study is expected to be used to predict the skin surface temperature on other thermal manikins as well. The empirical skin set equations at different ambient temperatures might be different, further skin studies should focus on other test temperatures. Similarly, all the skin empirical equations should be validated on some clothing scenarios.

\section{Acknowledgements}

This study was partially supported by VINNOVA (Research \& Grow Program) and by Taiga AB in Varberg, Sweden. The travel to the TBIS Symposium (Shanghai, 2010) was financially supported by the Sigfrid och Walborg Nordkvist Scholarship (No.76106) from Lund Institute of Technology and Lund University's Scholarship, Lund University, Sweden. We are grateful to Dr. Peter Bröde in Leibniz research Centre for Working Environment and Human Factors at Dortmund, Germany for the valuable comments on the statistical analysis. Finally, we thank the two reviewers for their criticisms on the previous version of the paper.
References:

[1] Endrusick T, Stroschein L, Gonzalez R. Thermal manikin history. Accessed on Sept. $9^{\text {th }}, 2009$. Available from http://www.mtnw-usa.com.

[2] Fan J, Chen Y. Measurement of clothing thermal insulation and moisture vapour resistance using a novel perspiring fabric thermal manikin. Meas Sci Technol 2002; 13: 1115-1123.

[3] Holmér I. Thermal manikin history and applications. Eur J Appl Physiol 2004; 92: 614618.

[4] Tamura T. Development of a two-layer movable sweating thermal manikin. Indus Health 2006; 44: 441-444.

[5] Kenzo S. The physiology, pharmacology, and biochemistry of the eccrine sweat gland. Rev Physiol Biochem Pharmacol 1977; 79: 51-131.

[6] Slegers JFG. The mechanism of sweat-secretion. PFLügers Archiv Eur J Physiol 1964; 279: 265273.

[7] Gao C, Holmér I. Initial, transient and steady state evaporative resistance of impermeable protective clothing. In: Fan J, editor. Proceedings of the 6th International Meeting on Thermal Manikin and Modeling (6I3M). Hong Kong, 2006; p. 253-261.

[8] Wang F, Gao C, Kuklane K., Holmér I. A study on evaporative resistances of two skins design for thermal manikin 'Tore' under different environmental conditions. J Fibre Bioeng Inform 2009; 1: 301-305.

[9] Meinander H. Experience with a sweating thermal manikin- Ready for standard use? In: Nilsson $\mathrm{H}$, Holmér I, editors. Proceedings of a European Seminar on Thermal Manikin Testing (IIMM). Stockholm: National Institute for Working Life, 1997. p. 38-42.

[10] Havenith G, Richards MG, Wang X, Bröde P, Candas V, den Hartog E, Holmér I, Kuklane K, Meinander H, Nocker W.. Apparent latent heat of evaporation from clothing: attenuation and heat pipe effects. J Appl Physiol 2008; 104: 142-149.

[11] Kuklane K, Heidmets S, Johansson T. Improving thermal comfort in an orthopaedic aid: better Boston brace for scoliosis patients. In: Fan J editor. Proceedings of the 6th International Meeting on Thermal Manikin and Modeling (6I3M). Hong Kong, 2006. p. 343-351.

[12] Wang F. A comparative introduction on sweating thermal manikins Newton and Walter. In: da Silva MCG editor. Proceedings of the 7th International Meeting on Thermal Manikin and Modeling (7I3M). Coimbra, 2008; p. 1-7. 
[13] ASTM F 2370. Standard test method for measuring the evaporative resistance of clothing using a sweating manikin. American Society for Testing and Materials, USA, 2005.

[14] EN ISO 15831. Clothing-physiological effects-measurement of thermal insulation by means of a thermal manikin. Brussels, Belgium: European Committee for Standardization, 2004.

[15] Nilsson H. Comfort climate evaluation with thermal manikin methods and computer simulation models. PhD Thesis, Royal Institute of Technology, 2004.
[16] Stark P. SticiGui, glossary of statistical terms. Accessed on March 10, 2010. Available from http://statistics.berkeley.edu/ stark/SticiGui/Text/g1 oss.htm\#mse.

[17] Cadarette B, Montain S, Kolka M, Stroschein L, Matthew W, Sawka M. Cross validation of USARIEM heat strain prediction models. Avia Space Environ Med 1999; 70: 996-1006. 